\title{
Analysing the composition of the SME sector in high- and low-income regions. Some research hypotheses
}

\author{
ISIDORO ROMERO ${ }^{1}$ \\ Department of Applied Economics, University of Seville, Seville, Spain
}

Please, quote the published version of this paper in the journal of Entrepreneurship and Regional Development, Vol. 23, Numbers 7-8, pp. 637-660.

Certain qualitative characteristics of the small and medium-sized enterprises (SMEs) operating within a territory might be essential to explain their macroeconomic impact. From this perspective, the current paper explores the relationship between the composition of the SME sector and the level of regional economic development. In this respect, a conceptual framework to analyse the composition of SME sectors is proposed considering two key aspects: on the one hand, different dimensions of SMEs' entrepreneurial orientation -innovation, cooperation, proactivity and quality orientation- and, on the other hand, the role of the external effects resulting from the inter-firm productive linkages within a specific area -differentiating between domestic, dependent, exporting and extravert SMEs. The relationship between these two key aspects is also considered and tested using a multinomial logit model. The empirical analysis uses data from a survey among over 650 SMEs in two Spanish provinces: Barcelona, as an example of a high-income economy, and Seville, as an example of a comparatively backward area.

Key words: small and medium-sized enterprises; regional development; enterprise policy; linkages; innovation.

\footnotetext{
${ }^{1}$ E-mail: isidoro@us.es
} 


\section{Analysing the composition of the SME sector in high and low-income regions. Some research hypotheses}

Certain qualitative characteristics of the small and medium-sized enterprises (SMEs) operating within a territory might be essential to explain their macroeconomic impact. From this perspective, the current paper explores the relationship between the composition of the SME sector and the level of regional economic development. In this respect, a conceptual framework to analyse the composition of SME sectors is proposed considering two key aspects: on the one hand, different dimensions of SMEs' entrepreneurial orientation -innovation, cooperation, proactivity and quality orientation- and, on the other hand, the role of the external effects resulting from the inter-firm productive linkages within a specific area -differentiating between domestic, dependent, exporting and extravert SMEs. The relationship between these two key aspects is also considered and tested using a multinomial logit model. The empirical analysis uses data from a survey among over 650 SMEs in two Spanish provinces: Barcelona, as an example of a high-income economy, and Seville, as an example of a comparatively backward area.

Key words: small and medium-sized enterprises; regional development; enterprise policy; linkages; innovation. 


\section{Introduction}

In the last decade, SMEs have drawn the attention of policy makers as a source to promote economic growth and lower unemployment rates (European Commission 2007, OECD 2007). This interest has been stimulated, since the economic crisis in the seventies, by different studies showing SMEs to be dynamic and contributing significantly to economic growth, job creation and innovation (Birch 1979, Storey 1988, Acs and Audretsch 1990, Davis et al. 1996, Johansson 2004, Carree et al. 2007). However, not all the studies reached exactly the same conclusions. Thus, Carree and Thurik (1999) showed that the size of the SME sector exerts a positive effect on economic growth in high-income countries in the European Union, but not in countries with lower income per capita, such as Spain or Portugal. This mixed evidence may be showing that, when analysing the economic impact of SMEs, it is not enough to consider quantitative aspects, such as the number of SMEs operating in a territory. On the contrary, certain qualitative characteristics of these SMEs might explain their different contributions to economic growth. In this sense, Verheul et al. (2006:435), when studying the effect of business ownership on unemployment in Spain, reach the conclusion that "the quantity of business ownership in Spain does not have a particularly large contribution to bringing down unemployment". However, they consider that, in addition to other factors, "an increase in the quality of business ownership in Spain may also have contributed to the recent decrease in the unemployment rate".

From this perspective, it seems necessary to delve into the diversity of the SME sector in order to assess its contribution to economic growth, job creation and innovation. In order to do so, the present work proposes a theoretical framework to analyse the composition of the SME sector considering two key aspects:

- Some essential dimensions of SME entrepreneurial orientation (EO) -innovation, cooperation, proactivity and quality orientation.

- The external effects resulting from the inter-firm productive linkages within a specific area.

Both factors -EO and external effects via regional linkages- are essential, in our opinion, to explain the macroeconomic impact of SMEs on regional development. In addition, the hypothesis that EO influences the spatial patterns of SME productive linkages is proposed. This interrelation has also implications for regional development 
since it might affect the transmission of knowledge through spillover effects, as will be discussed later on.

The empirical part of this paper aims to test these research hypotheses using firm data from a survey carried out among 659 SMEs in two Spanish provinces with very different per capita incomes: Barcelona, as an example of a highly-developed economy, and Seville, as an example of a relatively backward area. These micro data are used to identify different types of SMEs and are also aggregated in order to compare the final composition of the SME sectors in Barcelona and Seville. Consequently, this paper proposes an unusual approach, swinging between the microeconomic and macroeconomic levels of analysis.

The article is organised as follows: the second section presents a theoretical framework, built on a review of different sources of literature, to approach the mechanism through which SMEs can boost economic growth and job creation. This section ends with the presentation of three research hypotheses regarding the composition of the SME sector in regions with different levels of development. The third section is dedicated to the empirical analysis. In this section, the theoretical proposal is illustrated with a comparison between the characteristics and performance of the SME sectors in the provinces of Seville and Barcelona. The paper concludes with some final considerations and policy implications.

\section{A theoretical framework to analyse the composition of the SME} sector

This paper is built on the general hypothesis that regions with different levels of development are characterised by different compositions of their SME sectors. From this perspective, the aspects to be taken into account when studying the composition of the SME sectors should represent key mechanisms through which the microeconomic performance of SMEs in a territory might have a relevant macroeconomic impact. It is self-evident that the increases in firms' sales, employment and/or productivity represent an intermediate link for this connection. Among the factors which have been considered in the literature to explain these forms of firm growth, two aspects are especially meaningful for our purposes: the multiple dimensions of SME entrepreneurial orientation (EO) and the spatial patterns of SMEs' productive linkages. ${ }^{1}$ 
On the one hand, different aspects of EO have been pointed out as relevant factors related to the SMEs' performance and economic success (Lumpkin and Dess 1996, Wiklund and Shepherd 2005, Madsen 2007). Specifically, four dimensions of EO will be considered in this paper, namely: innovation, cooperation, proactivity and quality orientation.

Innovation is a major dimension of the SMEs' EO and a topic of great interest within the SME literature (Acs and Audretsch 1990, Link and Bozeman 1991, Kalantaridis and Pheby 1999). Whether SMEs are more or less innovative than large companies has been an extensively discussed issue, as well as the factors that foster SME innovation or the special characteristics of innovative SMEs. In any case, obviously not all SMEs are innovative and a relevant distinction has to be established between innovative SMEs and non-innovative or unadventurous ones.

Also cooperation and networks formation have been often considered as a strategic option for SMEs in order to overcome the limitations that small size poses for their growth or their attempts at innovation (Becattini et al. 1990, Lipparini and Sobrero 1994, Street and Cameron 2007). Different authors have tested the increase in efficiency derived from cooperation and have provided different typologies of SMEs and networks considering the role of alliances and collaborative relationships. From this perspective, a cooperative SME is expected to have a better performance than an isolated or 'autistic' one. Consequently, also in aggregate terms, an SME sector showing a dense network of cooperative links between firms is expected to have a higher efficiency, to exhibit a faster growth or introduce more innovations.

Proactivity and planning are other aspects related to the SMEs' EO which have merited wide attention. A proactive SME intends to anticipate and act on future needs through taking different dynamic initiatives to energize the business. In this sense, Guzmán and Santos (2001) have considered business planning as a characteristic behaviour of proactive entrepreneurs and SMEs. Many SMEs do not undertake any planning of their activities on a regular basis in contrast to the extensive planning systems developed within large companies. By means of planning, SMEs can anticipate and react to changes in the market.

Moreover, management literature has also analysed many other aspects of SME behaviour, identifying diverse styles of management and linking them with indicators of business performance (for example, Aragón-Sánchez and Sánchez-Marín 2005, Hutchinson et al. 2006). In this respect, the quality orientation might be also pointed out 
as an emerging strategic factor in SME management. The obtaining of quality certifications and industrial standards (ISOs or similar) is becoming increasingly important for SMEs (Casadesus and Giménez 2000, Briscoe et al. 2005), especially when they collaborate, as specialized suppliers, with large multinational corporations within 'Global Value Chains' (GVCs) (Kaplinsky and Readman 2001, Nadvi 2008).

From these previous findings in the theoretical and empirical literature it could be expected that SME sectors in high-growth regions should be characterised by a high proportion of innovative, cooperative, proactive and quality-orientated SMEs.

Nevertheless, studying the composition of the SME sector as a mere aggregation of the results of individual SMEs would not represent a fully satisfactory approach. A more comprehensive framework is presented in this paper, which includes the role of the externalities originated by individual SMEs and affecting other firms' growth. In this respect, productive linkages represent a type of externality which has been worthy of particular consideration in the literature. Thus, the endogenous growth models have emphasized the role of the technological spillovers as a source of increasing returns. In these models, the diffusion of knowledge resulting from the firm's investment increases the efficiency in the whole economy (Romer 1986, Romer 1990). These effects seem to appear more frequently in diversified productive systems due to a cross-fertilization among sectors (Glaeser et al. 1992, Henderson 1994), productive linkages being a probable route for them (Verspagen and De Loo 1999, Dietzenbacher and Los 2002). ${ }^{2}$ Furthermore, the 'New Economic Geography' has also considered the backward and forward linkages within formalized models as relevant factors in the spatial dynamic of the productive activity (Krugman 1991, Fujita et al. 1999). Thus, productive linkages are viewed as a type of externality that can lead to agglomeration economies when they are subject to a spatial constraint (Parr 2002, Parr et al. 2002). Finally, the economical impact of the externalities associated with the linkages has been broadly considered in the literature about industrial districts, local systems of firms and clusters (Becattini et al. 1990, Markusen 1996, Porter 1998).

In comparison to large enterprises, it is frequently supposed that SMEs show a higher level of territorial integration and maintain stronger linkages with local or regional suppliers and clients (Florio 1996, Crone and Watts 2000). For this reason, among others, the significance of SMEs in local and regional development has been emphasized in the endogenous development literature (Giaoutzi et al. 1988, Storey 1988). Nevertheless, dynamic SMEs can also often be found, which operate with 
external suppliers and export a high proportion of their production, actively participating in the globalization process (Acs and Yeung 1999, Audretsch 2003).

In this respect, Romero and Santos (2007) have recently proposed a firm typology which identifies diverse patterns of firm behaviour within a regional productive system. Specifically, they distinguish four SME models, namely: the 'domestic' SME, the 'exporting' SME, the 'dependent' SME and the 'extravert' SME (Figure 1). These models fulfil different functions within a regional productive system, so that each one has a different strategic relevance. The role of each SME model within the whole economy depends also on the SME's position inside value chains, so it is convenient to differentiate between the consumer-oriented SMEs which produce final products and the business-oriented SMEs whose production is essentially used as an input in other production processes.

a) The 'domestic' SME concentrates its activity within a region regarding its sales, as well as its input purchases. This lack of external projection reduces, from a macroeconomic perspective, the capacity of this type of enterprises to propel the economic regional growth. However, those domestic business-oriented SMEs which produce intermediate outputs might contribute to internally interconnect the regional productive system through productive linkages which can represent a channel of pecuniary and knowledge externalities.

b) The 'dependent' SME is the small or medium-sized firm whose suppliers are mainly situated outside the region and whose production is sold basically in the regional market. The net importing performance of this type of SME increases the regional level of external dependency. Furthermore, its impact on regional growth is limited by the absence of backward linkages and the size of the regional market. Consequently, this model of SME is not particularly interesting from an endogenous development perspective. However, dependent business-oriented SMEs producing intermediate outputs might have a relevant function as suppliers of other productive regional activities, participating in production chains that are, at least, partially endogenous. In these cases, they can contribute to improving the technological level and the productivity of other firms associated with them through forward linkages. 
c) The 'exporting' SME is the small or medium-sized firm whose production is principally sold in external markets -abroad or in other regions within the national economy- but whose main suppliers are situated in the region where it is located. Its exporting potential, which reflects a high level of competitiveness, along with its backward linkages within the regional productive system, provide this type of firm with a certain pulling power. Therefore, from a macroeconomic perspective, this model of enterprise might contribute to regional growth in a very positive way. This applies mainly for the consumer-oriented SMEs, since there are not many other potential forward steps in the productive chains that could increase the added value and the employment within the region.

d) The 'extravert' SME is the small or medium-sized firm whose activity is orientated towards external markets with regards to the sale of its products as well as the purchase of its inputs. This type of enterprise shows an intense exporting activity, which enlarges its growth potential through the sales in external markets. However, the extravert SME has weak forward and backward linkages with other firms within its regional productive system. Consequently, it does not generate significant pushing or pulling effects. Nevertheless, the external supply of inputs may constitute a source of competitiveness for these SMEs.

Moreover, Romero and Santos (2007) postulate that highly-developed regions frequently show an important presence of exporting and extravert SMEs -especially in knowledge and technology intensive activities- along with a dense population of domestic SMEs. On the contrary, backward regions might feature an abundance of dependent SMEs, especially in final sectors. Nonetheless, they only present the case of a backward region, using primary data from the regional input-output table and do not provide any evidence regarding high-income regions. Furthermore, their study is static and they do not explore the macroeconomic effects caused by the changes in the composition of the production system.

\section{INSERT FIGURE 2 ABOUT HERE}

Therefore, in order to study the composition of the SME sector, two aspects are considered in this article: the EO and the externalities associated with the spatial patterns of inter-firm linkages. In the theoretical model proposed (see Figure 2), EO leads to a better performance of the SME sector, fostering economic growth and 
employment creation -arrow (a) in Figure 2. In addition, the model assumes that EO influences the localization of the SMEs' sales and purchases, contributing to delimitate the spatial patterns of the SMEs' linkages -arrow (b) in Figure 2. Finally, inter-firm productive linkages play a significant role multiplying the effects of the individual firms' performance due to pecuniary and knowledge externalities -arrow (c) in Figure 2. Therefore, the model explores the connections between the microeconomic level of analysis -represented by individual SMEs- the mesoeconomic level -represented by the SME sector as a whole- and the macroeconomic level -represented by the regional economy.

Based on this theoretical framework, the three following hypotheses are postulated in this paper:

Hypothesis 1 (H1): High-growth economies are characterised by a high proportion of innovative, cooperative, proactive and quality-orientated SMEs with an EO -arrow (a) in Figure 2.

Hypothesis 2 (H2): SME sectors in highly-developed economies show a significant proportion of exporting and extravert SMEs -whereas SME sectors in backward economies are comparatively characterised by a larger proportion of domestic and dependent SMEs-arrow (c) in Figure 2. The former especially holds for consumeroriented SMEs.

Hypothesis 3 (H3): An SME's EO influences the spatial patterns of the SME's linkages -arrow (b) in Figure 2. Thus, the SMEs with a high EO are more likely to perform as extravert SMEs, whereas those SMEs with a low EO are more likely to perform as domestic SMEs.

Notice that $\mathrm{H} 3$ addresses the link between the microeconomic and the mesoeconomic levels of analysis, whereas $\mathrm{H} 1$ and $\mathrm{H} 2$ relate the mesoeconomic level to the macroeconomic one.

In the following section some evidence is provided regarding these hypotheses.

\section{Analysing the composition of the SME sector in Barcelona and} Seville

Barcelona and Seville are the main provinces in the regions of, respectively, Catalonia and Andalusia, the cities of Barcelona and Seville being the administrative 
capitals of these regions and the second and fourth most populated cities in Spain. Catalonia and Andalusia are two of the largest regions in Spain, with respect to both their geographical extension and their participation in the total national population and GDP. Despite these similarities, the two regions represent antagonistic poles in terms of their income and development levels in the Spanish context. Andalusia, in the south of the peninsula, is one of the less advanced regions of Spain, while Catalonia, in the north-east, is one of the driving forces of the national economy. Thus, Seville's GDP per capita was $67.6 \%$ of Barcelona's in 2007. Furthermore, unemployment rates in Andalusia and Seville are more than double the rates in Catalonia and Barcelona, respectively, as may be observed in Table 1. Consequently, Seville and Barcelona are two very illustrative cases when making interregional comparisons within the Spanish context.

Seville's economy also exhibits a business density markedly lower than Barcelona's due to the greater importance of self-employment in Barcelona (see also Table 1). Despite this, Seville's economy is characterised by a lower average firm size as a consequence of the higher participation of large companies in Barcelona. As a result of all this, the total size of the SME sector within the Seville economy-measured by the percentage of workers employed in SMEs- turns out to be larger than in the case of Barcelona. This holds also for the percentage of SMEs with respect to the total number of firms. In consequence, in the simple comparison between these two economies, the one with a higher income shows a smaller SME sector. In this respect, the size of the SME sector apparently does not seem to play a positive role for regional development in these two cases.

However, despite its comparatively backward situation, Seville's economy has experienced a higher economic growth in comparison to Barcelona's in recent years, as shown in Table 1. Obviously, many factors are behind the income gap between these two regions and the catching-up process recently observed and it is not the aim of this paper to delve into all of them. Historical reasons, such as the failure of the industrialization process in Seville in the $19^{\text {th }}$ century or the more peripheral situation in the case of Seville versus the proximity to the European core economies in the case of Barcelona have influenced the regional development trajectories in the long run. For the more recent trends, the economic effects of migration flows, the process of convergence regarding the sectoral production structure (for the period 2002-07 see Table 1), the impact of structural and cohesion European funds or the negative effect of some 
delocalization processes by large industrial companies -especially affecting Barcelona's economy- contribute to explaining the economic performance of both economies (Lacomba 1993, García-Greciano and Raymond 1999, Fernández-Otheo et al. 2007). However, leaving these factors aside, this paper explores whether the analysis of the composition of their SME sectors might provide some additional light for these developments.

\section{INSERT TABLE 1 ABOUT HERE}

\subsection{Data and indicators}

The empirical part of this paper uses data from a survey among 659 SMEs in the provinces of Seville (169 firms interviewed in 2002 and 263 in 2007) and Barcelona (227 firms interviewed in 2007). ${ }^{3}$ This survey was conducted between March and September in 2002 and 2007 by the research group 'SMEs and Economic Development' of the University of Seville within a research project financed by the Department of Employment and the Department of Innovation, Science and Enterprise of the Regional Government of Andalusia.

Following the European Commission's standards, firms with less than 250 employees were considered SMEs. The data were collected through on-site interviews of business owners or managers. Firms surveyed were randomly selected from directories of SMEs located in industrial and business parks (38\% response rate). The sample framework was designed to be representative of Seville and Barcelona economies regarding the distribution by sector and size. SMEs operating in industry and services were interviewed, whereas the primary sector was excluded. The KolmogorovSmirnov test was applied to check sample representativeness. No significant bias was found between respondents and non-respondents regarding total revenue.

An initial version of the questionnaire was tested in fifteen pilot interviews. Considering the results of this first stage, the questionnaire was modified introducing some improvements. Since it is usually difficult to find owners or managers willing to cooperate with researchers and provide detailed information about their businesses, the questionnaire was designed with their reluctance in mind in order to facilitate their answers. The final questionnaire included, among other issues, different questions which provide information about the location of suppliers and clients and also about the 
dimensions of the SMEs' EO considered in the previous section. Specifically, five questions related to the localization of the sales markets and another five to the localization of suppliers. In these questions the owners/managers were requested to indicate the approximate percentage ('none', 'up to 10\%', 'between 10 and 25\%', 'between 25 and $50 \%$ ', 'more than $50 \%$ ' or ' $100 \%$ ') of the total sales that were made, respectively, in the provincial market, in the rest of the regional market, in the rest of the national market, and in the rest of the world (see Figure 3). The same was asked with respect to their intermediate purchases and the localization of their suppliers. All this information was summarized in two indexes of extraversion -one for the sales and another one for the purchases- which were obtained as follows (see also Figure 3):

1. The mid point of each interval indicated before was established as a class mark $\left(m_{i}\right)$.

2. A weight for each geographic market, $w_{i}$, was introduced as follows: 0 for the provincial market, 0.2 for the rest of the regional market, 0.5 for the rest of the national market, and 1 for the rest of the world.

3. The two synthetic indexes were defined to capture the extraversion of the sales $(S E)$ and the purchases $(P E)$, as follows:

$$
S E(P E)=\frac{\sum_{i} w_{i} \cdot m_{i}^{s(p)}}{\sum_{i} m_{i}^{s(p)}}
$$

\section{INSERT FIGURE 3 ABOUT HERE}

The indexes of SE and PE were calculated as weighted averages of each market for each firm. In fact, the numerator in (1) could itself represent an index of extraversion. Nevertheless, the denominator $\sum_{i} m_{i}^{s(p)}$ in expression (1) was introduced to make a pertinent correction because of the use of class marks instead of real percentages. If $m_{i}^{s(p)}$ denoted the exact percentages of the sales and purchases in each market, it would hold that $\sum_{i} m_{i}^{s(p)}=1$. However, because $m_{i}^{s(p)}$ represent mark-classes that is not necessary true. That could imply a slight overestimation or underestimation of the extraversion indexes which can be faced by means of introducing the denominator in expression (1). ${ }^{4}$ The resulting indexes of SE and PE take values from 0 to 1 , 
indicating the level of extraversion of the SME regarding its sales or its purchases, respectively (higher values of the indexes reflect higher levels of extraversion). Next, these indexes were used to establish empirical definitions for the different SME models according to the typology presented in the previous section. In order to do this, the value of 0.5 was set for both ratios as a threshold to differentiate between the SME models. ${ }^{5}$ Thus, each SME model was defined as follows (Table 2):

\section{INSERT TABLE 2 ABOUT HERE}

As mentioned before, the role of these models within a regional production system depends also on the position of SMEs in production chains. In this respect, it is convenient to distinguish between consumer-oriented SMEs, which produce mainly final outputs, and business-oriented SMEs, which produce essentially intermediate outputs used by other firms in their own production processes. In order to do so, an indirect method was employed in this paper. Those firms which sell their production to final consumers have naturally a low level of concentration of their sales with specific clients. On the contrary, those SMEs producing intermediate products for other companies might face a higher concentration of their sales with a small number of important clients. This situation is specifically evident for those SMEs which supply particular components to large multinational corporations coordinating GVCs, but a significant level of concentration might also occur even for SMEs providing intermediate inputs to other SMEs. In this paper, the level of concentration of the sales with the ten most important clients was used as a proxy indicator to identify businessoriented SMEs. Thus, those SMEs which concentrated less than $25 \%$ of their sales with their ten most important clients were considered consumer-oriented, whereas those SMEs which concentrated $25 \%$ or more of their sales with their ten most important clients were considered business-oriented firms.

Moreover, the survey also provided data about different aspects of the firm's performance. Among them, the following four dimensions of the SME dynamism were specifically included in the analysis:

- Innovation and research and development activities. The SMEs interviewed were asked whether in the previous three years they had carried out the following four innovative activities: 
a) Product innovation (PROD_IN) -including radical and incremental innovations and also small improvements in the firm's products.

b) Process innovation (PROC_IN) -including radical and incremental innovations and also an adaptation or mere incorporation of existing technology.

c) Research and Development activities (R\&D).

d) Patents (PATENT).

These four innovative activities were included in the analysis as dummy variables which take the value 1 if the firm had undertaken the activity or 0 in the negative case.

- Cooperation (COOP). The owners/managers were asked whether they had undertaken any cooperation activity with any other firms within the previous three years. In this respect, both formal agreements and informal relationships in production, R\&D, marketing or other aspects of business activity were considered. The answers were also treated as a dummy variable ( 1 for cooperative firms and 0 for non-cooperative ones).

- Proactivity. Business planning (PLAN) was considered as a characteristic of a proactive SME and also included in the analysis as a dummy.

- Quality orientation (Q_CERT). Owners/managers were asked whether their firms had obtained any quality certification or industrial standards and the result was coded again as a dummy variable.

Consequently, seven variables defined in a binary way (the value 1 for the entrepreneurial activities and 0 for the non-entrepreneurial ones) were considered in the analysis aiming to capture the EO of the SMEs.

Also, three control variables were included in the analysis:

- Firm size. This was given by the number of employees (EMP).

- Sector. Two sectors were differentiated, namely, industry versus services. The variable IND takes the value 1 for industry (ISIC Rev. 4 codes 10-43) and 0 for services (ISIC Rev. 4 codes 45-96).

- Province: The variable PROV takes the value 0 in the case of firms in Barcelona and 1 in the case of those in Seville.

Some descriptive results for these indicators are shown in Table 3. 


\subsection{Results}

The empirical analysis presented in this section consists of two different exercises:

- The first one puts forward the aggregated data in order to compare the composition of the SME sectors in Barcelona and Seville. This first exercise aims to illustrate and test $\mathrm{H} 1$ and $\mathrm{H} 2$.

- The second exercise addresses H3. Thus, using the data for individual firms, the effect of EO on spatial patterns of firm linkages is tested in a multinomial logit model.

\subsubsection{Comparing the composition of SME sectors in Barcelona and Seville}

When comparing the aggregated composition of the SME sectors in Barcelona and Seville considering the EO and the SME typology some interesting differences can be appreciated.

Firstly, Seville's economy, along with a higher growth rate than Barcelona's, also shows a comparatively dynamic performance of the SMEs regarding the entrepreneurial dimensions previously considered. This result is coherent with H1 which states that high-growth areas are characterised by an SME sector with a high proportion of entrepreneurial-oriented firms. As can be seen in Table 4, among the seven indicators of EO, the SME sector in Barcelona only shows a clear superiority in terms of quality certifications, whereas in the Seville economy, despite its lower level of development, the SMEs exhibit a significantly superior performance with respect to cooperation, product innovation and process innovation. The SME sector in Barcelona also shows better results with respect to $R \& D$ activities and patents, but these latter differences are not statistically-significant. In any case, regarding innovation, Barcelona appears to present a better record in terms of formal innovation activities leading to radical and incremental innovations, whereas Seville's SMEs have made a great catching-up effort in recent years, introducing more technologically-advanced products and processes to approach the efficient production frontier. Finally, no relevant differences can be observed between Barcelona and Seville SME sectors regarding business planning. In conclusion, though the Seville economy is still a less competitive one than Barcelona's, SMEs in Seville have shown a quite satisfactory trajectory in terms of entrepreneurial activities in recent years. This improvement in the composition 
of the SME sector in the Seville economy might have contributed to its positive macroeconomic evolution.

\section{INSERT TABLE 4 ABOUT HERE}

Secondly, when considering the composition of the SME sectors according to the SME typology, domestic SMEs were shown to be the most representative ones in both provinces (see Figure 4). Nevertheless, statistically-significant differences can be appreciated between the composition of the SME sector in Barcelona and Seville (the Chi-square statistic takes the value 36.820 and the p-value 0.000 ), which are in common for both business-oriented and consumer-oriented SMEs (see Table 5). These differences are in line with $\mathrm{H} 2$. Thus, on the one hand, in a comparatively more developed area, such as Barcelona, the SME sector shows a larger participation of extravert and exporting SMEs. These SMEs are capable of competing in external markets and, specifically in the case of exporting SMEs, may generate pulling effects with a positive impact on the rest of the provincial economy. On the other hand, the Seville economy is characterised by a remarkably greater participation of domestic SMEs and also by a larger proportion of dependent SMEs. In addition, as can be seen in Table 5, in the Seville economy the participation of dependent SMEs is especially high in consumer-oriented firms producing final goods and services. These dependent SMEs, besides contributing negatively to the trade balance, might perform in many cases as 'market-maker' firms (Guzmán et al. 2006). These market-maker firms act as instruments or appendices for large companies settled in highly-developed areas which use them to capture external final markets. They mainly assume distribution, commercial and marketing functions or very simple transformation processes and have a limited capacity of generating income and employment in the region where they operate.

\section{INSERT FIGURE 4 ABOUT HERE}

The differences in the composition of the SME sectors in Barcelona and Seville cannot be attributed to differences in the sectoral structure of their economies (see Table 5). Thus, the participation of domestic and dependent SMEs is higher in Seville than in 
Barcelona both in the industry and the services sector; whereas the participation of exporting and extravert SMEs is lower in Seville than in Barcelona in both sectors.

However, as previously said, Seville has shown in recent years a more intense economic growth in comparison to Barcelona which might have been caused, among other reasons, by an improvement in the composition of the SME sector. In this respect, it is meaningful to consider the changes in the composition of the SME sector in the Seville economy in the 2002-07 period. This transformation in SME activities has led to a reduction in the proportion of domestic SMEs, mainly, in consumer-oriented activities. Furthermore, in 2007 a higher presence of exporting and extravert SMEs in both business-oriented and consumer-oriented activities can be observed in comparison to 2002, which represents another improvement in the composition of the SME sector. ${ }^{6}$ This tendency can be observed as well for both the industry and the services sectors. Nevertheless, an increase in the participation of dependent SMEs can also be appreciated due to the consumer-oriented firms in the industrial sector. In this respect, additional efforts by local and regional administrations might be pertinent in order to foster the competitiveness and the access to external markets for those dependent SMEs operating in consumer-oriented activities.

\section{INSERT TABLE 5 ABOUT HERE}

\subsubsection{Entrepreneurial orientation and SME models}

This section aims to test whether EO influences firm decisions regarding the spatial patterns of SME linkages, leading to different SME models. In this case, the two key aspects to analyse the composition of the SME sector would appear to be interconnected, as stated in $\mathrm{H} 3$.

Given the fact that four alternative SME models have been proposed, the subsequent polytomous discrete decision was modelled using a multinomial logit specification (Maddala 1999, Hosmer and Lemeshow 2000). In this four-category model there were six possible logit functions to be estimated, giving the probability to perform as: (1) an extravert SME versus a domestic SME, (2) an extravert SME versus a dependent SME, (3) an extravert SME versus an exporting SME, (4) a dependent SME versus a domestic SME, (5) a dependent SME versus an exporting SME, and (6) an exporting SME versus a domestic SME. 
Let $\mathbf{x}$ denote the vector of the independent variables -the EO dimensions and the control variables ${ }^{7}$ - for the SME model $j-j$ being domestic, dependent, exporting or extravert SME. The probability $p_{j}$ that a firm -as a result of its EO- fitted into the model $j$ was determined as follows:

$$
\begin{aligned}
& p_{j}=\frac{\exp \left(\mathbf{x}^{\prime} \beta_{j}\right)}{1+\sum_{j=1}^{m-1} \exp \left(\mathbf{x}^{\prime} \beta_{j}\right)} \quad j=1, \ldots, m-1 \\
& p_{m}=\frac{1}{1+\sum_{j=1}^{m-1} \exp \left(\mathbf{x}^{\prime} \beta_{j}\right)}
\end{aligned}
$$

where $j$ represents the SME models - $m$ being the reference model- and $\beta_{j}$ stands for the vector of coefficients for model $j$. So, it holds that $\sum_{j=1}^{m} p_{j}=1$. The model estimates the odds ratio of fitting into the $j$ SME model relative to the $m$ reference model, that is, $\frac{p_{j}}{p_{m}}$

\section{INSERT TABLE 6 ABOUT HERE}

Table 6 shows the results for the regression model estimated from the surveys in Barcelona and Seville in 2007. As can be observed, the model was statisticallysignificant, according to the Chi-square test, at a level of significance of 0.000 , so the null hypothesis that there was no difference between the models 'with' and 'without' independent variables was rejected. Furthermore, none of the coefficients for the independent variables had an estimated standard error larger than 2.0, so neither multicollinearity, nor other numerical problems were manifested (Hosmer and Lemeshow 2000: 141). The estimated model correctly predicts $68.8 \%$ of the cases. The usual explanatory statistics to test the coefficients significance are also reported in Table 6.

According to the estimation results, extravert SMEs seem to be the most entrepreneurial ones among the four models. As shown in Table 6, when comparing extravert SMEs with the other SME models -regressions (1), (2) and (3)- the signs of all 
the statistically significant coefficients for the EO indicators are negative (results for the control variables will be commented on later). That implies that the probability of fitting into any model versus performing as an extravert SME decreases for those SMEs with an EO. From the opposite perspective, the EO increases the probability of performing as an extravert SME (versus performing as any other SME model). The latter is specifically applicable to R\&D activities, planning and quality-certifications -when comparing extravert SMEs with domestic SMEs- process innovation -when comparing extravert SMEs with dependent SMEs, and R\&D activities and planning -when comparing extravert SMEs with exporting SMEs.

Dependent and exporting SMEs are situated in an intermediate situation regarding their EO. On the one hand, the probability of performing as a domestic SME versus fitting into the dependent SME model decreases for those quality-orientated SMEs which carry out R\&D and planning activities -regression (4). Notice that, on the contrary, the coefficients' signs for process innovation and cooperation are positive in the regression, indicating better results for these dimensions of EO in the case of domestic SMEs. However, the effect in the case of process innovation is only marginally significant (at a level of 0.1 ). On the other hand, the probability of performing as a domestic SME versus operating as an exporting one decreases for those SMEs with patents and carrying out product innovations -as the negative coefficients indicate in regression (6). Finally, when comparing dependent SMEs with exporting ones -see regression (5), dependent SMEs seem to be characterised by a superior EO. Thus, the probability of operating as an exporting SME versus fitting into the dependent SME model decreases for those firms undertaking R\&D and planning activities.

In conclusion, these results support $\mathrm{H} 3$, which states that EO influences the spatial patterns of SME linkages, increasing the probability of a firm performing as an extravert SME and diminishing the probability of its performing as a domestic SME. With respect to the control variables, the number of employees is only a significant factor when explaining the probability of operating as a domestic SME versus an exporting one -regression (6). This probability increases with firm size. Sector is a significant variable in regression (4) regarding domestic SMEs. In this respect, SMEs in industry are more likely to operate as domestic firms than as dependent ones. Furthermore, the multinomial logit model shows that the location in Seville or Barcelona is a major statistically-significant factor when explaining the spatial patterns of the SMEs' productive linkages, even after controlling by sectoral composition, firm 
size or the SMEs' EO. Thus, the probability of fitting into the domestic and dependent models in comparison with the extravert model is significantly larger for those located in Seville -regressions (1) and (2). The same conclusion is also applicable when comparing domestic and dependent SMEs with exporting SMEs -regressions (5) and (6). This confirms the results supporting H2 previously presented in Section 3.2.1.

\section{Conclusion and policy implications}

Entrepreneurship and SMEs have attracted the attention of academics and policy-makers in the last decade as driving forces of economic growth and employment creation. Though substantial research results have been obtained in this respect, two future challenges might be identified in this field:

- On the one hand, the issue has been approached in most cases from a quantitative perspective, attending exclusively to firm creation and the size of the SME sector. On the contrary, the qualitative dimension of the phenomenon has not been sufficiently explored, delving into the SME diversity and the composition of the SME sector in an economy.

- On the other hand, two sources of literature might be differentiated in this area. A first one, developed at the microeconomic level, studies the consequences of SME management for firm performance. A second one, developed at the macroeconomic level, is interested in the effects of entrepreneurship and SMEs on economic growth and employment creation and destruction. However, those two approaches are often considerably disconnected, so that a need for the integration of the microeconomic and the macroeconomic considerations in a systemic framework emerges in this field.

This article has tried to tentatively face those two challenges by means of suggesting an exploratory analytical framework to approach the impact of the SMEs on regional development. This theoretical contribution is built on two key interrelated aspects:

- Firstly, the entrepreneurial orientation (EO) of SMEs towards innovation, cooperation, proactivity and quality orientation. In this paper, we have defended the hypothesis that SME sectors in high-growth economies are characterised, in aggregate terms, by a high presence of innovative, cooperative, proactive and quality-orientated firms. 
- Secondly, the external effects generated by individual SMEs, especially those associated with productive linkages, through which economic impacts are spread over other firms located in the same area. In this paper, the distinction between domestic, dependent, exporting and extravert SMEs has been defended as a useful conceptual tool to study the composition of the SME sector.

The analytical capacity of this framework has been illustrated comparing the composition of the SME sectors in Barcelona and Seville using data from surveys conducted in both economies. Though Barcelona has a much higher GDP per capita than Seville, the latter one has experienced a faster economic growth in recent years. Of course, the differences between these two economies regarding their levels of regional development and their recent economic results cannot be attributed exclusively to the performance of their SME sectors. However, this paper explores the possibility that both facts might be partially explained by the structural characteristics and the ongoing changes in their SME sectors. Thus, on the one hand, in line with the hypothesis proposed in this paper, Barcelona shows a higher presence of extravert and exporting SMEs in comparison to Seville, whereas the SME sector in Seville is characterised by a larger proportion of domestic and dependent SMEs. On the other hand, some improvements in the composition of the SME sector in the Seville economy have been observed in recent years. In this respect, the presence of exporting and extravert SMEs has increased and SMEs in the Seville economy have exhibited a comparatively good performance regarding entrepreneurial activities with respect to those in Barcelona.

In addition, in this paper the hypothesis is defended that there is a relationship between these two dimensions considered to analyse the composition of the SME sector. Thus, empirical evidence has been provided regarding the impact of the SMEs' EO on the spatial patterns of the SMEs' productive linkages. In this respect, those SMEs with a sound EO have been shown to be more likely to perform as extravert SMEs, whereas those with a more conservative management are more likely to fit into the domestic SME model. These results have relevant implications from the perspective of regional development. In spite of the positive role played by domestic SMEs internally interconnecting the regional production system, an excessive predominance of this firm model, especially regarding consumer-oriented activities, could represent a limitation for the regional economy. In those cases, though domestic SMEs could be the source for pecuniary and/or knowledge spillovers within the regional production system, these effects are in practice not very significant since these domestic SMEs are 
not usually innovative, cooperative, proactive or quality-orientated. On the contrary, though extravert SMEs are especially innovative and quality-orientated, their role as sources of knowledge and pecuniary spillover effects might be frequently limited by their low productive connection with the regional production system through backward and forward linkages. In this respect, exporting SMEs in consumer-oriented activities via backward linkages- and dependent SMEs in business-oriented activities -via forward linkages- might make a significant contribution as a source of pecuniary and knowledge spillovers.

The approach proposed in this paper implies a bottom-up research strategy, from the microeconomic characteristics of SMEs in a territory to the macroeconomic performance of the economies. This type of analysis is very demanding in terms of data. Thus, representative databases of the SMEs in a certain number of regions would be necessary in order to robustly test the research hypotheses proposed in this paper. This work proposes an analytical framework to study the composition of the SME sector. It also provides some empirical support to illustrate the potential of this approach to investigate the impact of SMEs in regional development. However, much more empirical research is needed in order to confirm the hypotheses put forward here.

Finally, these results have direct implications regarding the design of SME policy. Actions aiming to boost entrepreneurship and support the SME sector should not concentrate on encouraging new firm creation without additional considerations. These policies should be undertaken with selective criteria, intending to support SMEs with an EO and to improve the composition of the SME sector. Public intervention should focus on catalysing cooperative projects between SMEs and introducing incentives for entrepreneurial activities such as innovation or the obtaining of quality certifications instead of implementing horizontal support measures for all the entrepreneurs and SMEs. These entrepreneurial activities could also foster the competitiveness of SMEs which would allow them to gain a greater presence in external markets, contributing to transform domestic and dependent SMEs operating in final sectors into exporting and extravert SMEs. Furthermore, stimulus measures aiming to encourage these entrepreneurial initiatives by domestic, dependent and exporting SMEs could contribute to increase the regional productivity as a result of spillover effects transmitted -via regional linkages- throughout the regional economy. 


\title{
Acknowledgements
}

The author wishes to express his gratitude to the anonymous reviewers for their helpful comments on earlier versions of this paper. This research was financed by the Department of Employment and the Department of Innovation, Science and Enterprise of the Regional Government of Andalusia (Spain).

\begin{abstract}
Notes
1. For other conditioning factors see also Donckels and Lambrecht (1996), Davidsson et al. (2002), or Moreno and Casillas (2007).

2. Of course, spillover effects are not transmitted necessarily via productive linkages. An extensive literature in regional economics has addressed the role of disembodied technical knowledge and 'untraded interdependencies' (Storper 1995). However, even in these cases, interpersonal relationships between workers and entrepreneurs of firms involved in buyer-seller interaction might constitute a natural source for information and knowledge flows.

3. SMEs interviewed in 2007 were not the same as those participating in the previous survey in 2002.

4. For instance, let us consider a firm A which sells $100 \%$ of its production in the rest of the regional market. Then $\sum_{i} m_{i}^{s}=1$. In this case the value of SE would be the same if we consider the definition in (1) or we simply use its numerator. However, let us consider firm B which sells $1 / 3$ in the rest of the regional market, $1 / 3$ in the rest of the national market and $1 / 3$ in the rest of the world. In this case, all the class-marks would be 0.375 and $\sum_{i} m_{i}^{s}=1.125$. If SE was defined only by the expression in the numerator, the SE would take the value 0.6375 which might imply a slight overestimation of the real level of extraversion due to the use of class-marks. Considering the expression in (1) the SE is 0.5667 for firm B. The opposite would happen in the case of firm C which sells $47 \%$ in the rest of the regional market, $47 \%$ in the rest of the national market and $6 \%$ in the rest of the world. In this case, $\sum_{i} m_{i}^{s}=0.375+0.375+0.05=0.8$. If only the numerator in (1) was considered, SE would be 0.3125 .
\end{abstract}

This value might be underestimating the real level of extraversion. Using the definition in (1) the SE is 0.3906 .

5. In order to assure a rigorous comparison, using the same criteria to calculate the indexes for the two provinces is the key issue, and not the specific values established for the market weights or the threshold for the extraversion indexes. The weights here adopted determine that exporting products (importing inputs) to the rest of the world is necessary to reach values larger than 0.5 for the sales (purchases) extraversion index. The latter assures that an SME concentrating $100 \%$ of its sales and $100 \%$ of its purchases on the national market is necessarily classified as a domestic SME, regardless of how those sales and purchases are distributed between the provincial, the rest of the regional market and the rest of the national market. Other alternative definitions for the indexes were tested without significant changes in the conclusions of this paper.

6. This improvement cannot be attributed to a better macroeconomic context. We will consider in this respect the three previous years to the moment of each survey (2002 and 2007) since some of the questions in the surveys were related to the performance of the SMEs interviewed in such a period (see description of the variables in Section 3.1). Thus, the average growth rate in constant terms of the GDP in Spain in the period $1999-2002$ was $4.03 \%$ and $3.61 \%$ in the period $2004-07$.

7. The distinction between consumer-oriented and business-oriented SMEs was also incorporated as a dummy in previous regressions. However, it was not statistically significant in any case, so we dropped it in the final regression. 


\section{References}

Acs, Z.J. and Audretsch, D.B. 1990. Innovation and Small Firms. Cambridge, MA: MIT Press.

Acs, Z.J. and Yeung, B. (eds.) 1999. Small and Medium-Sized Enterprises in the Global Economy. Michigan: University of Michigan Press.

Aragón-Sánchez, A. and Sánchez-Marín, G. 2005. Strategic Orientation, Management Characteristics, and Performance: A Study of Spanish SMEs. Journal of Small Business Management 43, 3: 287-308.

Audretsch, D.B. (ed.) 2003. SMEs in the Age of Globalization. Cheltenham: Edward Elgar.

Becattini, G., Pyke, F., and Sengenberger, W. 1990. Industrial Districts and Inter-Firm Co-operation in Italy. Geneva: International Labor Studies.

Birch, D. L. 1979. The job generation process. Cambridge: MIT Program on Neighbourhood and Regional Change.

Briscoe, J.A., Fawcett, S.E., and Todd, R.H. 2005. The Implementation and Impact of ISO 9000 among Small Manufacturing Enterprises. Journal of Small Business Management 43, 3: 309-330.

Carree, M.A., Van Stel, A., Thurik, R. and Wennekers, S. 2007. The relationship between economic development and business ownership revisited. Entrepreneurship \& Regional Development 19, 3: 281-291.

Carree, M.A. and Thurik, R. 1999. Industrial Structure and Economic Growth. In Innovation, Industry Evolution and Employment, ed. D. B. Audretsch and A. R. Thurik, 86-110. Cambridge: Cambridge University Press.

Casadesus, M. and Giménez, G. 2000. The benefits of the implementation of the ISO 9000 standard: empirical research in 288 Spanish companies. The TQM Magazine 12, 6: 432.

Crone, M. and Watts, H.D. 2000. MNE supply linkages and the local SME sector: Evidence from Yorkshire and Humberside. Local Economy 15, 4: 325-337.

Davidsson P., Kirchhoff B., Hatemi, J.A. and Gustavsson, H. 2002. Empirical analysis of business growth factors using Swedish data. Journal of Small Business Management 40, 4: 332-349.

Davis, S.T., Haltiwanger, J.C. and Schuh, S. 1996. Small Business and Job Creation: Dissecting the Myth and Reassessing the Facts. Small Business Economics 8, 4: 297-315.

Dietzenbacher, E. and Los, B. 2002. Externalities of R\&D Expenditures. Economic Systems Research 14, 407-425.

Donckels, R. and Lambrecht, J. 1996. A holistic approach to the expansion decision of small-and medium-sized enterprises in a metropolitan area. The case of Brussels. Entrepreneurship \& Regional Development 8, 1: 19-36.

European Commission 2007. Small and medium-sized enterprises - Key for delivering more growth and jobs. A midterm review of Modern SME policy. Communication from the Commission to the Council, the European Parliament, the European Economic and Social Committee and the Committee of the Regions. COM(2007) 592 final. Brussels: European Commission.

Fernández-Otheo, C.M., Labrador, L., Myro, R. (2007): Deslocalización de empresas y actividades productivas en España: una primera aproximación. Mediterráneo económico 11: 57-78.

Florio, M. 1996. Large firms, entrepreneurship and regional development policy: 'growth poles' in the Mezzogiorno over 40 years. Entrepreneurship \& Regional Development 3: 263-295.

Fujita, M., Krugman, P. and Venables, A.J. 1999. The Spatial Economy. Massachusetts: Massachusetts Institute of Technology.

García-Greciano, B. and Raymond, J.L. 1999. Las disparidades regionales y la hipótesis de convergencia: Una revisión. Papeles de Economía Española 80: 2-18.

Giaoutzi, M., Nijkamp, P. and Storey, D.J. 1988. Small is Beautiful - The Regional Importance of Smallscale Activities. In Small and Medium-size Enterprises and Regional Development, ed. M. Giaoutzi, P. Nijkamp and D.J. Storey, 1-18. London: Routledge.

Glaeser, E.L., Kallal, H.D., Scheinkman, J.A. and Shleifer, A. 1992. Growth in Cities. Journal of Political Economy 100: 1126-1152.

Guzmán, J., and Santos, J. 2001. The booster function and the entrepreneurial quality: An application to the province of Seville. Entrepreneurship \& Regional Development 13: 221-228.

Guzmán, J., Santos, F.J., Cáceres, F.R., Romero, I., and Liñán, F. 2006. Realidad Empresarial y Desarrollo Económico en la provincia de Sevilla. Seville: Consejo Andaluz de Relaciones Laborales and Mergablum.

Henderson, J.V. 1994. Where does an industry locate? Journal of Urban Economics 35: 83-104.

Hosmer, D. W. and Lemeshow, S. 2000. Applied logistic regression. New York: John Wiley and Sons.

Hutchinson, K., Quinn, B., and Alexander, N. 2006. The role of management characteristics in the internationalisation of SMEs. Evidence from the UK retail sector. Journal of Small Business and Enterprise Development 13, 4: 513-534. 
Johansson, D. 2004. Is small beautiful? The case of the Swedish IT industry. Entrepreneurship \& Regional Development 16, 4: 271-287.

Kalantaridis, C. and Pheby, J. 1999. Processes of innovation among manufacturing SMEs: The experience of Bedfordshire. Entrepreneurship \& Regional Development 11: 57-78.

Kaplinsky, R. and Readman, J. 2001. Integrating SMEs in Global Value Chains. Towards Partnership for Development. Vienna: United Nations Industrial Development Organization (UNIDO).

Krugman, P. 1991. Increasing returns and economic geography. Journal of Political Economy 99: 483499.

Lacomba, J.A. 1993. La economía andaluza: Una perspectiva histórica. In Estructura económica de Andalucia, ed. M. Martín, 21-72. Madrid: Espasa Calpe.

Link, A.N., and Bozeman, B. 1991. Innovative Behavior in Small-Sized Firms. Small Business Economics 3, 3: 179-184.

Lipparini, A. and Sobrero, M. 1994. The Glue and the Pieces: Entrepreneurship \& Innovation in Smallfirm Networks. Journal of Business Venturing 9: 125-140

Lumpkin G.T. and Dess G.G. 1996. Clarifying the entrepreneurial orientation construct and linking it to performance. Academy of Management Review 21: 135-172.

Maddala, G.S. 1999. Limited-dependent and qualitative variables in econometrics. Cambridge University Press: Cambridge.

Madsen, E.L. 2007. The significance of sustained entrepreneurial orientation on performance of firms - A longitudinal analysis. Entrepreneurship \& Regional Development 19, 2: 185-204.

Markusen, A. 1996. Sticky places in slippery spaces: a typology of industrial districts. Economic Geography 72: 293-313.

Moreno, A.M. and Casillas, J.C. 2007. High-growth SMEs versus non-high-growth SMEs: A discriminant analysis. Entrepreneurship \& Regional Development 19, 1: 69-88.

Nadvi, K. 2008. Global standards, global governance and the organization of the global value chains. Journal of Economic Geography 8: 323-343.

Parr, J.B. 2002. Missing elements in the analysis of agglomeration economies, International Regional Science Review 25: 151-168.

Parr, J.B., Hewings, G.J.D., Jungyul, S. and Nazara, S. 2002. Agglomeration and trade: Some additional perspectives. Regional Studies 36(6): 675-684.

Porter, M.E. 1998. On Competition. Harvard Business School Publishing: Boston.

Romer, P.M. 1990. Endogenous technological change. Journal of Political Economy 98 (5): 71-102.

Romer, P. M. 1986. Increasing returns and long-run growth. Journal of Political Economy 94 (5): 10021037.

Romero, I. and Santos, F.J. 2007. Firm Size and Regional Linkages. A Typology of Manufacturing Establishments in Southern Spain. Regional Studies 41, 5: 571-584.

Storey D.J. 1988. The role of small and medium-sized enterprises in Europe job creation. In Small and medium-sized enterprises and regional development, ed. M. Giaotzi, P. Nijkam and D.J. Storey, 40160. London: Routlege.

Storper, M. 1995. The Resurgence of Regional Economies, Ten Years Later: The Region as a Nexus of Untraded Interdependencies. European Urban and Regional Studies 2: 191 - 221.

Street, C.T. and Cameron, A.-F. 2007. External Relationships and the Small Business: A Review of Small Business Alliance and Network Research. Journal of Small Business Management 45, 2: 239-266.

Verheul, I., Van Stel, A., Thurik, R. and Urbano, D. 2006. The Relationship between Business Ownership and Unemployment in Spain: A Matter of Quantity or Quality? Estudios de Economía Aplicada 242:435-457.

Verspagen, B. and De Loo, I. 1999. Technology spillovers between sectors and over time, Technological Forecasting and Social Change 60: 215-235.

Wiklund, J. and Shepherd, D. 2005. Entrepreneurial orientation and small business performance: A configurational approach. Journal of Business Venturing 20: 71-91. 
Figure 1. SME typology according to the spatial patterns of productive linkages.

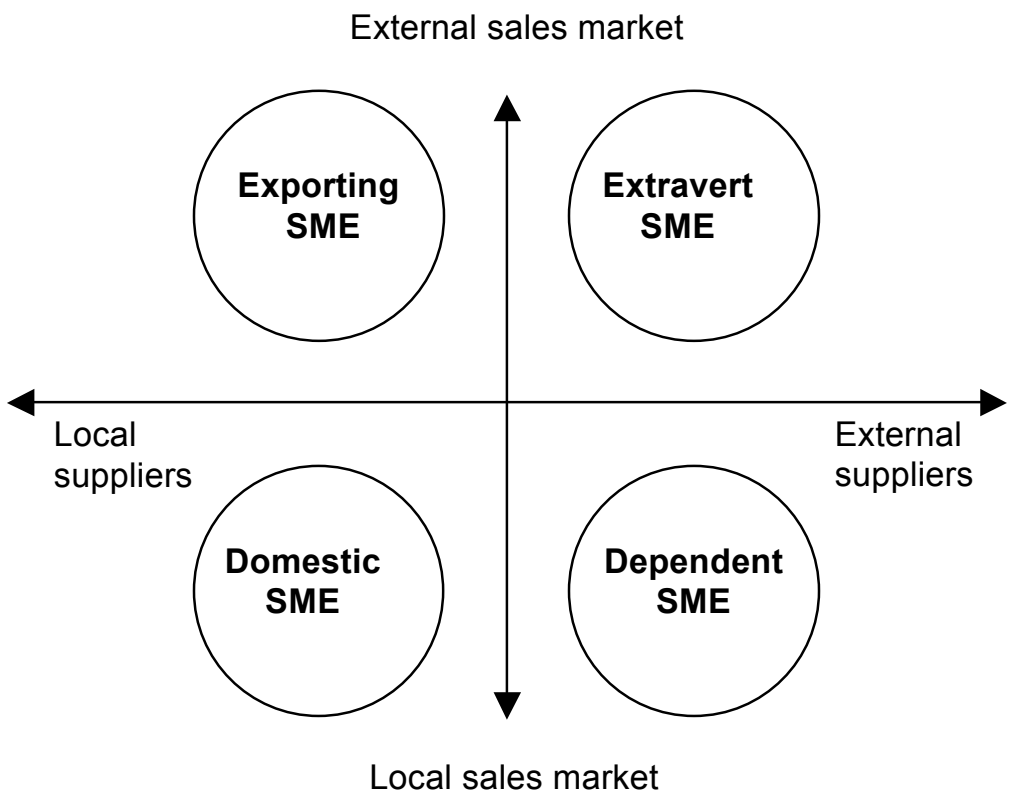

Source: Adapted from Romero and Santos (2007) 
Figure 2. Theoretical Framework.

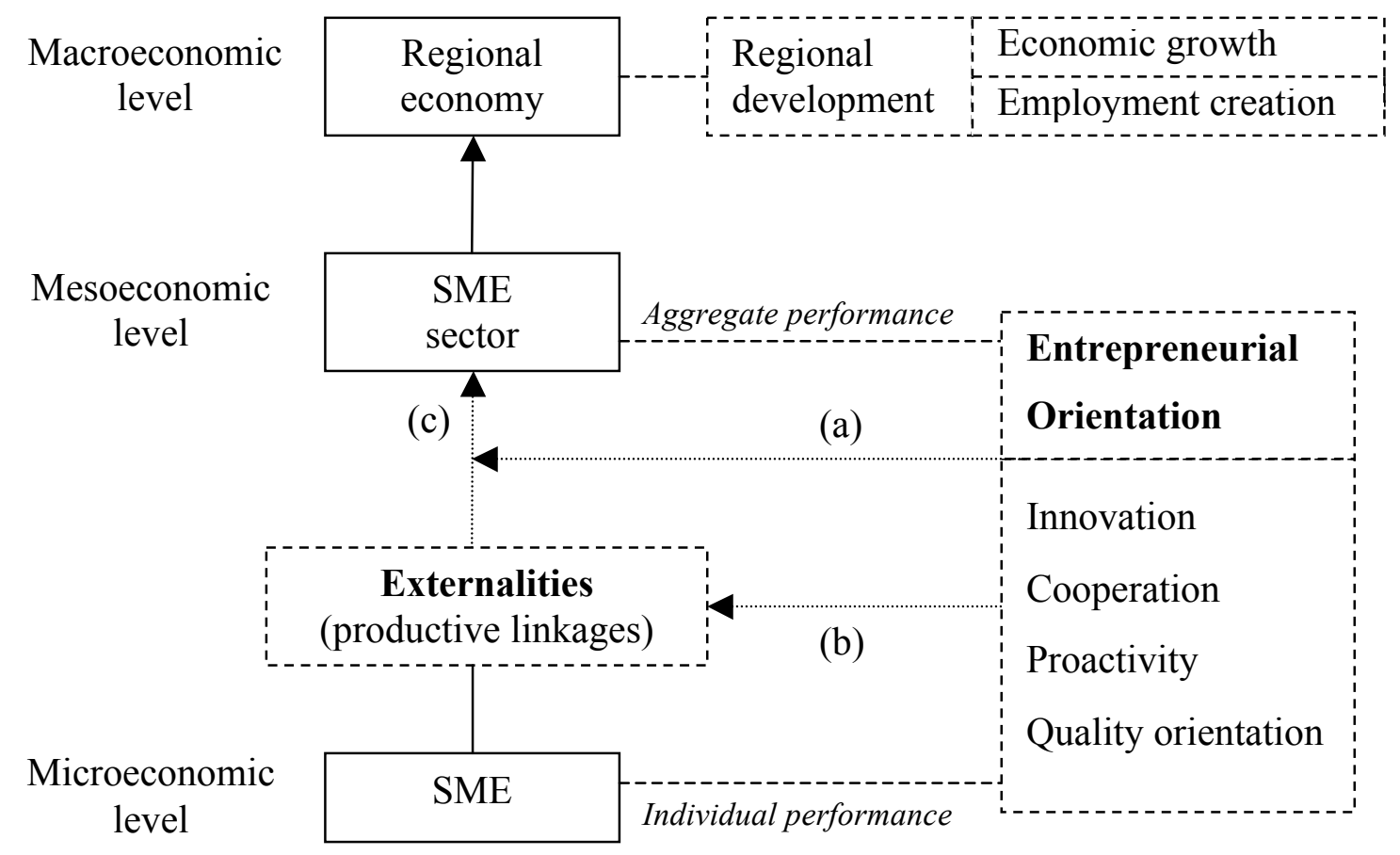


Figure 3. Construction of the purchase and sales extraversion indexes.

Question: What approximate percentage of the total sales (purchases) is made in the provincial market, the rest of the regional market, the rest of the national market and the rest of the world?

\begin{tabular}{|c|c|c|c|c|c|c|c|c|}
\hline & & 0 & 0.05 & 0.175 & 0.375 & 0.75 & 1 & $\begin{array}{c}\text { Class } \\
\text { marks } \\
\left(\mathbf{m}_{\mathbf{i}}\right)\end{array}$ \\
\hline & & None & $\begin{array}{c}\text { Up to } \\
10 \%\end{array}$ & $\begin{array}{c}10- \\
25 \%\end{array}$ & $\begin{array}{c}25- \\
50 \%\end{array}$ & $\begin{array}{l}\text { More } \\
\text { than } \\
50 \%\end{array}$ & $100 \%$ & Intervals \\
\hline 0 & Provincial market & $\square$ & $\square$ & $\square$ & $\square$ & $\square$ & $\square$ & \\
\hline 0.2 & Rest of the regional market & $\square$ & $\square$ & $\square$ & $\square$ & $\square$ & $\square$ & \\
\hline 0.5 & Rest of the national market & $\square$ & $\square$ & $\square$ & $\square$ & $\square$ & $\square$ & \\
\hline 1 & Rest of the world & $\square$ & $\square$ & $\square$ & $\square$ & $\square$ & $\square$ & \\
\hline $\begin{array}{l}\text { Market } \\
\text { weights } \\
\left(w_{i}\right)\end{array}$ & Spatial markets & & & & & & & \\
\hline
\end{tabular}


Figure 4. Composition of the SME sector in Barcelona and Seville.

$\because$ Dependent SMEs

$\square$ Domestic SMEs

$\square$ Exporting SMEs

Extravert SMEs

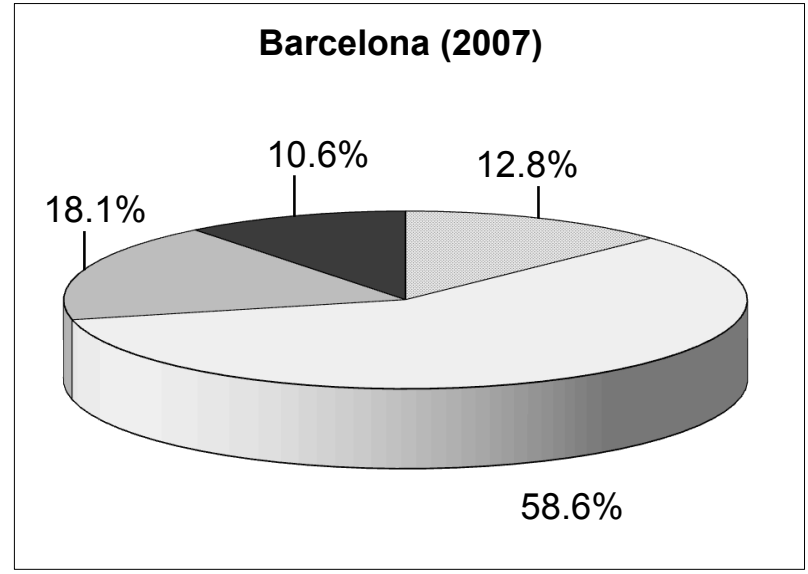

Seville (2007)
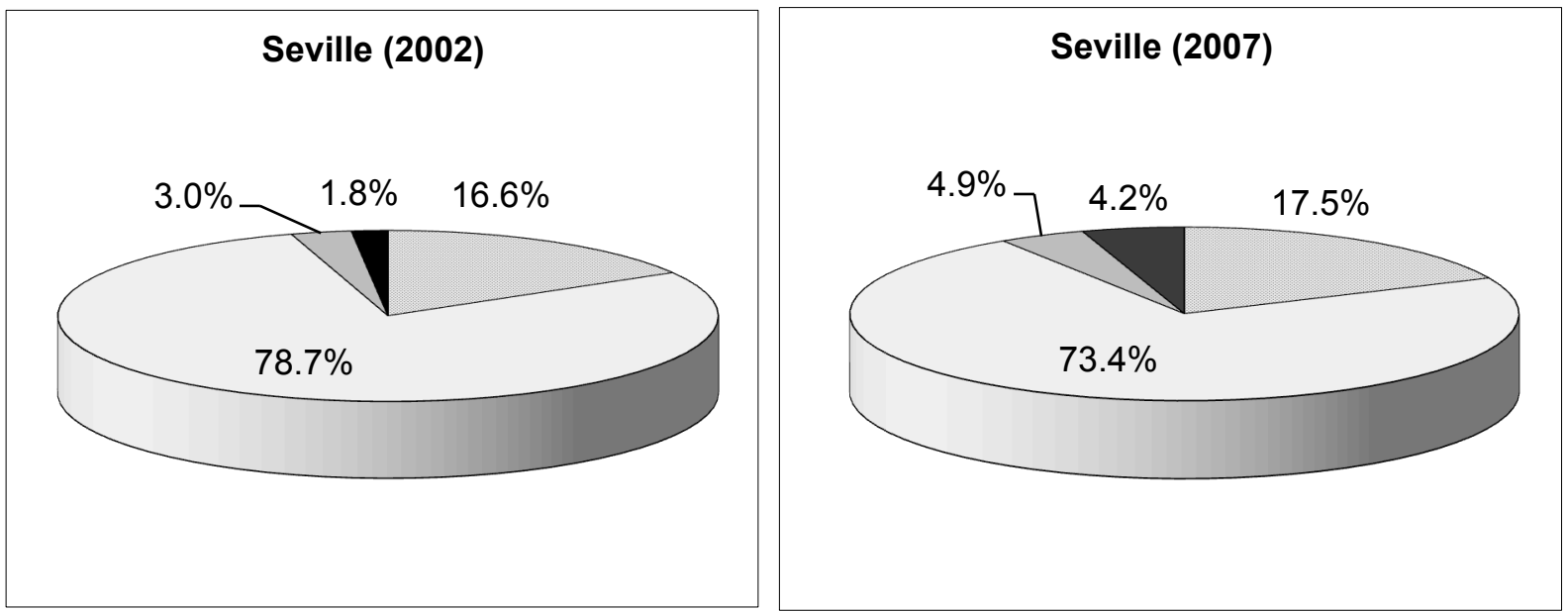
Table 1. Some indicators for the Barcelona's and Seville's economies.

\begin{tabular}{|c|c|c|c|}
\hline & $\begin{array}{c}\text { Barcelona } \\
\text { (2007) }\end{array}$ & $\begin{array}{l}\text { Seville } \\
(2007)\end{array}$ & $\begin{array}{l}\text { Seville } \\
(2002)\end{array}$ \\
\hline Population ( $\mathrm{n}^{\circ}$ inhabitants) & 5332,513 & 1849,268 & 1758,720 \\
\hline Unemployment rate $(\%)^{1}$ & 6.46 & 13.22 & 20.85 \\
\hline Business establishments (per 100 inh.) & 8.80 & 6.25 & 5.61 \\
\hline Average number of workers per firm ${ }^{2}$ & 11.05 & 10.18 & 9.66 \\
\hline Self-employed (per 100 inh.) & 4.77 & 4.02 & 4.53 \\
\hline $\mathrm{SMEs}^{3}$ (\% of the number of firms) & 99.77 & 99.85 & 99.88 \\
\hline Workers in $\mathrm{SMEs}^{4}$ (\% of the number of workers) & $68.2^{5}$ & $71.8^{5}$ & n.a. \\
\hline Primary sector (\% of total employment) & 0.99 & 4.53 & 5.93 \\
\hline Secondary sector (\% of total employment) & 30.47 & 24.14 & 20.65 \\
\hline \multirow[t]{2}{*}{ Tertiary sector (\% of total employment) } & 68.54 & 71.33 & 73.42 \\
\hline & \multicolumn{2}{|c|}{ Barcelona } & Seville \\
\hline GDP per capita (euros). 2007 & \multicolumn{2}{|c|}{$27,448.28$} & $8,559.75$ \\
\hline GDP growth rate $2000-07(\%)^{6}$ & \multicolumn{2}{|c|}{3.45} & 4.61 \\
\hline
\end{tabular}

Source: Calculated from data of the National Institute of Statistics and the National Institute of Social Security.

(1) Last quarter. (2) Including self-employment. (3) Firms with less than 250 employees. (4) Firms with less than 200 employees. (5) Data only available for the year 2006. (6) Average annual growth rate in real terms calculated using the consumer prices index for each province. 
Table 2. Extraversion indexes and SME typology.

Index of Purchase Extraversion (PE)

\begin{tabular}{c|c|c|c|}
\cline { 3 - 4 } \multicolumn{1}{c|}{} & $\mathrm{PE} \leq 0.5$ & $\mathrm{PE}>0.5$ \\
\cline { 2 - 4 } \multicolumn{1}{c}{ Index of Sales } & $\mathrm{SE} \leq 0.5$ & Domestic SME & Dependent SME \\
\cline { 2 - 4 } Extraversion (SE) & $\mathrm{SE}>0.5$ & Exporting SME & Extravert SME \\
\hline
\end{tabular}

Table 3. Entrepreneurial orientation and SME models. Descriptive results.

\begin{tabular}{lccccc}
\hline & $\begin{array}{c}\text { Domestic } \\
\text { SMEs }\end{array}$ & $\begin{array}{c}\text { Dependent } \\
\text { SMEs }\end{array}$ & $\begin{array}{c}\text { Exporting } \\
\text { SMEs }\end{array}$ & $\begin{array}{c}\text { Extravert } \\
\text { SMEs }\end{array}$ & Total \\
\hline PROD_IN (\%Yes) & 51.1 & 52.6 & 60.9 & 55.6 & 52.8 \\
PROC_IN (\%Yes) & 60.9 & 52.5 & 58.7 & 70.4 & 60.1 \\
R\&D (\% Yes) & 21.8 & 29.8 & 19.6 & 59.3 & 25.3 \\
PATENT (\% Yes) & 6.4 & 10.5 & 19.6 & 14.8 & 9.1 \\
COOP (\% Yes) & 41.0 & 22.8 & 26.1 & 33.3 & 32.3 \\
PLAN (\% Yes) & 55.3 & 80.7 & 58.7 & 88.9 & 61.6 \\
Q_CERT (\% Yes) & 43.2 & 64.9 & 60.9 & 81.5 & 51,0 \\
IND (\% ind.) & 41.0 & 22.8 & 26.1 & 33.3 & 36.1 \\
EMP (mean) & 25.1 & 33.4 & 40.5 & 23.7 & 28.0 \\
\hline
\end{tabular}

Note: The results by province are shown in Figure 4. 
Table 4. Entrepreneurial orientation of SMEs in Barcelona and Seville.

Results for the Chi-square test.

\begin{tabular}{|c|c|c|c|c|c|c|c|c|}
\hline & & PROD_IN & PROC_IN & R\&D & PATENT & COOP & PLAN & Q_CERT \\
\hline \multicolumn{2}{|c|}{ Barcelona } & 45.4 & 55.5 & 28.2 & 11.0 & 26.0 & 61.2 & 65.2 \\
\hline \multicolumn{2}{|c|}{ Seville } & 62.7 & 66.3 & 21.3 & 6.5 & 48.2 & 62.1 & 32.0 \\
\hline \multirow{2}{*}{$\begin{array}{l}\text { Chi- } \\
\text { square } \\
\text { test }\end{array}$} & Value & 11.697 & 4.682 & 2.438 & 2.378 & 9.749 & 0.033 & 42.847 \\
\hline & Sig. & $0.001(* *)$ & $0.030(*)$ & 0.118 & 0.123 & $0.002(* *)$ & 0.856 & $0.000(* * *)$ \\
\hline
\end{tabular}

(*) Differences statistically significant at the 0.05 level; (**) Differences statistically significant at the 0.01 level; $(* * *)$ Differences statistically significant at the 0.001 level.

Table 5. Composition of the SME sector in Barcelona and Seville according to the firms' market and the sector(\%).

\begin{tabular}{lccc|cccc}
\hline $\begin{array}{l}\text { Business- } \\
\text { oriented }\end{array}$ & $\begin{array}{c}\text { Barcelona } \\
(2007)\end{array}$ & $\begin{array}{c}\text { Seville } \\
(2007)\end{array}$ & $\begin{array}{c}\text { Sevilla } \\
(2002)\end{array}$ & $\begin{array}{c}\text { Consumer- } \\
\text { oriented }\end{array}$ & $\begin{array}{c}\text { Barcelona } \\
(2007)\end{array}$ & $\begin{array}{c}\text { Seville } \\
(2007)\end{array}$ & $\begin{array}{c}\text { Seville } \\
(2002)\end{array}$ \\
\hline Dependent SME & 14.0 & 13.0 & 15.7 & Dependent SME & 13.8 & 23.1 & 19.4 \\
Domestic SME & 57.0 & 76.7 & 79.4 & Domestic SME & 61.5 & 69.2 & 76.1 \\
Exporting SME & 17.0 & 5.5 & 2.9 & Exporting SME & 17.4 & 2.6 & 1.5 \\
Extravert SME & 12.0 & 4.8 & 2.0 & Extravert SME & 7.3 & 5.1 & 3.0 \\
Total & 100 & 100 & 100 & Total & 100 & 100 & 100 \\
\hline \multirow{2}{*}{ Industry } & Barcelona & Seville & Seville & Services & Barcelona Seville & Seville \\
& $(2007)$ & $(2007)$ & $(2002)$ & & $(2007)$ & $(2007)$ & $(2002)$ \\
\hline Dependent SME & 11.0 & 17.6 & 8.2 & Dependent SME & 15.4 & 16.7 & 22.1 \\
Domestic SME & 65.8 & 73.9 & 85.2 & Domestic SME & 55.9 & 70.1 & 74.1 \\
Exporting SME & 13.7 & 4.3 & 3.3 & Exporting SME & 19.1 & 6.9 & 1.9 \\
Extravert SME & 9.5 & 4.2 & 3.3 & Extravert SME & 9.6 & 6.3 & 1.9 \\
Total & 100 & 100 & 100 & Total & 100 & 100 & 100 \\
\hline
\end{tabular}


Table 6. EO and SME models. Multinomial logistic regression.

\begin{tabular}{|c|c|c|c|c|c|c|c|}
\hline \multicolumn{4}{|c|}{ Reference category EXTRAVERT SME } & \multicolumn{4}{|c|}{ Reference category: DEPENDENT SME } \\
\hline $\begin{array}{l}\text { (1) DOMESTIC } \\
\text { SME }\end{array}$ & B & $\begin{array}{l}\text { Stand. } \\
\text { Error }\end{array}$ & Sig. & $\begin{array}{l}\text { (4) DOMESTIC } \\
\text { SME }\end{array}$ & B & $\begin{array}{l}\text { Stand. } \\
\text { Error }\end{array}$ & Sig. \\
\hline PROD_IN & -0.104 & 0.556 & 0.851 & PROD_IN & 0.156 & 0.356 & 0.662 \\
\hline PROC IN & -0.085 & 0.657 & 0.897 & PROC IN & $1.106 \dagger$ & 0.387 & 0.070 \\
\hline R\&D & $-1.022 \dagger$ & 0.540 & 0.059 & R\&D & $-0.914^{*}$ & 0.403 & 0.023 \\
\hline PATEN & -0.198 & 0.689 & 0.774 & PATENT & -0.072 & 0.650 & 0.911 \\
\hline $\mathrm{COOP}$ & 0.262 & 0.523 & 0.616 & COOP & $1.000^{*}$ & 0.400 & 0.012 \\
\hline PLAN & $-1.749^{*}$ & 0.784 & 0.026 & PLAN & $-1.098 * *$ & 0.382 & 0.004 \\
\hline Q_CER & $-1.481^{*}$ & 0.666 & 0.026 & Q_CERT & $-0.805^{*}$ & 0.354 & 0.023 \\
\hline PROV & $1.294 *$ & 0.625 & 0.039 & PROV & -0.544 & 0.356 & 0.127 \\
\hline IND & -0.016 & 0.480 & 0.973 & IND & $0.711^{*}$ & 0.359 & 0.048 \\
\hline EMP & -0.000 & 0.007 & 0.943 & EMP & 0.003 & 0.004 & 0.447 \\
\hline $\begin{array}{c}\text { (2) DEPENDENT } \\
\text { SME }\end{array}$ & B & $\begin{array}{l}\text { Stand. } \\
\text { Error }\end{array}$ & Sig. & $\begin{array}{c}\text { (5) EXPORTING } \\
\text { SME }\end{array}$ & B & $\begin{array}{l}\text { Stand. } \\
\text { Error }\end{array}$ & Sig. \\
\hline PROD_IN & -0.260 & 0.614 & 0.672 & PROD_IN & 0.6 & 0.511 & 0.192 \\
\hline PROC_IN & $-1.192 \dagger$ & 721 & 0.094 & PROC_IN & 0.409 & 0.560 & 0.465 \\
\hline R\&D & -0.107 & 0.609 & 0.860 & R\&D & $-1.543^{*}$ & 0.628 & 0.014 \\
\hline PATENT & -0.125 & 0.835 & 0.881 & PATENT & 1.250 & 0.799 & 0.118 \\
\hline COOP & -0.738 & 0.607 & 0.224 & COOP & 0.893 & 0.561 & 0.112 \\
\hline PLAN & -0.650 & 0.847 & 0.442 & PLAN & $-0.990 \dagger$ & 0.514 & 0.054 \\
\hline Q_CERT & -0.676 & 0.723 & 0.349 & Q_CERT & -0.275 & 0.503 & 0.585 \\
\hline PROV & $1.837 * *$ & 0.680 & 0.007 & PROV & $-2.673 * * *$ & 0.646 & 0.000 \\
\hline & .727 & 0.555 & 0.190 & IND & 0.447 & 0.498 & 0.370 \\
\hline EMP & -0.003 & 0.007 & 0.647 & EMP & -0.005 & 0.005 & 0.353 \\
\hline \multirow{2}{*}{$\begin{array}{c}\text { (3) EXPORTING } \\
\text { SME }\end{array}$} & \multirow[b]{2}{*}{ B } & \multirow{2}{*}{$\begin{array}{l}\text { Stand. } \\
\text { Error }\end{array}$} & \multirow[b]{2}{*}{ Sig. } & \multicolumn{4}{|c|}{ Reference category: EXPORTING SME } \\
\hline & & & & $\begin{array}{l}\text { (6) DOMESTIC } \\
\text { SME }\end{array}$ & B & $\begin{array}{l}\text { Stand. } \\
\text { Error }\end{array}$ & Sig. \\
\hline PROD_IN & 0.406 & 0.655 & 0.536 & PROD_IN & $-0.751 \dagger$ & 0.427 & 0.053 \\
\hline PROC_IN & -0.783 & 0.757 & 0.301 & PROC_IN & 0.697 & 0.460 & 0.130 \\
\hline R\&D & $-1.650 *$ & 0.710 & 0.020 & R\&D & 0.629 & 0.546 & 0.250 \\
\hline PATENT & 1.125 & 0.811 & 0.165 & PATENT & $-1.322 *$ & 0.602 & 0.028 \\
\hline COOP & 0.154 & 0.641 & 0.809 & COOP & 0.107 & 0.449 & 0.811 \\
\hline PLAN & $-1.641 \dagger$ & 0.849 & 0.053 & PLAN & 0.108 & 0.401 & 0.788 \\
\hline Q_CERT & -0.951 & 0.752 & 0.206 & Q_CERT & -0.530 & 0.407 & 0.193 \\
\hline PROV & -0.836 & 0.824 & 0.310 & PROV & $2.130 * * *$ & 0.577 & 0.000 \\
\hline IND & -0.280 & 0.580 & 0.629 & IND & 0.264 & 0.398 & 0.508 \\
\hline EMP & 0.008 & 0.007 & 0.279 & EMP & $0.007 \dagger$ & 0.004 & 0.062 \\
\hline
\end{tabular}

Log-likelihood: 595.336. Chi-Square test of the model: 120.358. Significance level: 0.000. Mc Fadden $R^{2}: 0.165$. Nagelkerke $R^{2}: 0.319$. Cox and Snell $R^{2}: 0.273$

$(\dagger)$ Differences statistically significant at the 0.10 ; level; $(*)$ Differences statistically significant at the 0.05 level; (**) Differences statistically significant at the 0.01 level; $(* * *)$ Differences statistically significant at the 0.001 level. 